Research Article

\title{
The use of Turbidity and Total Suspended Solids Correlation for the Surface Water Quality Monitoring
}

\author{
Laura Kusari $^{\mathrm{a}^{*}}$ and Figene Ahmedi ${ }^{\mathrm{a}}$ \\ University of Prishtina, Faculty of Civil Engineering and Architecture, Kodra e Diellit, p.n. 10000 Prishtina, Kosovo
}

Accepted 10 September 2013, Available online 01 October 2013, Vol.3, No.4 (October 2013)

\begin{abstract}
The deterioration of surface water quality is a huge environmental concern in our new country. Recently we are witnessing the changes in land use throughout the country. Catchments modified from mainly agricultural to urban landuse. The River Sitnica Catchment is experiencing those uncontrolled changes even more rapidly. The agricultural land in this catchment is being progressively covered by new structures, mainly houses and roads, resulting in an increase of the imperviousness of that area and consequently the increased surface runoff. In addition, considerable industrial development and surface mining activities are taking place in this area, too. These changes are associated with high population growth rates and migration from other less urbanized areas. All the mentioned factors are imposing enormous stress on the catchment's rivers. In particular, urban river reaches are experiencing increase of almost all constituents, mostly oxygen demand, conductivity, total suspended solids and phosphorus. Concentrations of nutrients are also higher in those urban river reaches, too. Knowing that sediments are actually the most widespread cause of surface water impairment, than the Total Suspended Solids (TSS) is an important water quality monitoring parameter. The increase of urban, industrial and agricultural discharges into surface waters in this catchment is expected to cause an increase of this constituent, too. The Total Suspended Solids analysis provides an initial and very basic measure for characterization and study of surface water quality. Measuring the TSS in streams is necessary both for monitoring stream quality and for planning management actions for protection. But, since the TSS measurement is relatively expensive and time consuming procedure, especially for our new country, it is the aim of this work to represent a possibility to measure TSS through turbidity, as an easy to measure parameter. In order to know the relationship between turbidity and TSS, the frequent sampling and their laboratory analyses are required. To avoid this, due to time, financial and personnel limitations the new approach is used in this work. The laboratory prepared subsamples will provide the necessary data for the development of turbidity to TSS relationship.
\end{abstract}

Keywords: urban river reaches, Total Suspended Solids, turbidity, relationship

\section{Introduction}

Our environment is altered everyday as a result of the anthropogenic activities taking place within it. As land is cleared for construction and new roads, large amount of sediments are delivered into our streams. Furthermore, our rivers, in particular urban ones, are being polluted with discharges from untreated municipality wastewater, industrial wastewater discharge, mining activities, leachate from waste disposal areas as well as agricultural runoff. As a result, there is an increase in almost all constituents, as well as an increase of turbidity and Total Suspended Solids.As known, there are too many water quality parameters to be measured and also there are several

*Corresponding author Dr. sc. Laura Kusari and Dr. sc. Figene Ahmedi are working in University of Prishtina factors that affect the reliability and the outcome of those measurements. Usually, monitoring of surface waters and the measurements of these constituents is within time frames that are previously determined and as a result, it usually misses the event discharges (Kusari, 2012). It is a rather time consuming and intensive process. Therefore, a new approach of using one easy to measure parameter instead of another more expensive and time consuming one is a focus of this work. One component of water quality, total suspended solids is a significant indicator of physical and aesthetic degradation and a good indicator of other pollutants (particularly nutrients and metals) (James J. Packman, 1999). The aim of this work is to have an insight of the values of TSS in urban streams through the measurements of turbidity. The turbidity is chosen as a surrogate for TSS because of the simplicity of its measurements. Turbidity also describes the changes in sediment concentration during precipitations and can be used in evaluating pollution loads attached to sediment 
particles. To achieve this, the relationship between turbidity and TSS must be developed.

Since there isn't a universal correlation between turbidity and TSS then the relationship is site specific. For the development of such a relationship in selected location, frequent sampling and measurement of turbidity and TSS are needed. However, because of the constraints in time, personnel and finances of this research, different approach is used. Laboratory subsamples are prepared, each of them with different turbidity and TSS concentrations. The results gained from the laboratory analysis of subsamples provide the data necessary for the development of the turbidity to TSS relationship.

The relationship, if such exists for selected location, will be developed by applying linear regression analysis.

The results gained would enable the use of turbidity as a water quality indicator. Monitoring the turbidity along a river would provide valuable information on the sediments quantity and at the same time would prevent the need of frequent sampling and conducting expensive sediment analyses. The relationship may also be suitable for monitoring wastewater treatment effluent, dredging operations and dredged material disposal operations, discharges from mining activities and suspended sediments in storm water.

The prediction of pollutants entering a stream by conducting turbidity measurement, followed by the use of the relationship, would enable a reliable, rapid and costeffective water resources management (Kusari, 2012).

\section{Site Descriptions}

Amongst the most important components of the research methodology is study site selection. Therefore, it is done carefully, after consideration of the suitability of the sites to conduct field investigations. Kosovo is a young country that is experiencing higher population growth and it is estimated that in the year 2000, about 2.4 million inhabitants were living here (Islami, 2003). Besides, it ranks amongst the first countries in Europe, based on the population density, which is about 220 inhabitants $/ \mathrm{km}^{2}$. The higher density is in capital city Prishtina, where over 900 inhabitants are living in one square kilometre (Ministry of Environment and Spatial Planning, 2010).

In our country rural to urban migration is very present due to the lack of infrastructure and the distance from education and health centres. This increased number of people heading to urban areas imposes higher stress to receiving surface waters. This is also associated with a large number of new constructions and changes in land use destination, often without the consent of urban planners. And the trend continues upward.

The urbanization's impact on the surface waters is going to be a huge environmental concern due to the fact that the actual health of streams is very low. It will continue to deteriorate, knowing the fact that according to the strategic plan $2010-2020+$, this area is planned for industrial and economic growth, which will impose further stresses on surface waters.

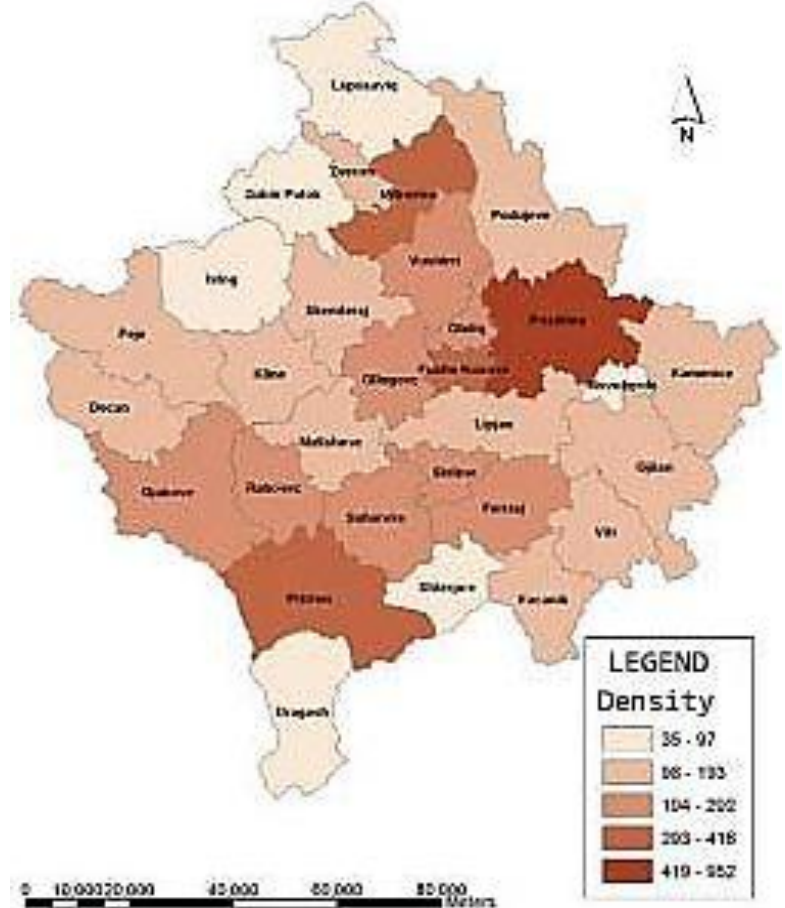

Fig. 1. Population density at municipalities Source: (Ministry of Environment and Spatial Planning, 2010)

Considering all the mentioned facts, the central part of Sitnica catchment was selected for this part of the research. The Sitnica catchment lies on the central part of Kosova and is characterized with medium- continental climate, with some impact of Aegean- Adriatic climate in this area. The average annual temperature is (10.2-10.4) ${ }^{\circ}$ $\mathrm{C}$, minimal temperature is $-26{ }^{\circ} \mathrm{C}$ while the maximum temperature reaches up to $37.4^{\circ} \mathrm{C}$ (Kosova, 2010).

The Sitnica catchment covers an area of $2931.71 \mathrm{~km}^{2}$ with the catchment's average slope $4.4 \%$. The average annual rainfall value is $691 \mathrm{~mm}$ and average annual flow is $16.6 \mathrm{~m}^{3} / \mathrm{s}$ (Kosova, 2010).

The Sitnica catchment's vegetative cover comprises mainly of arable land $\left(1277.68 \mathrm{~km}^{2}\right)$, meadows (436.4 $\mathrm{km}^{2}$ ), forests $\left(339.9 \mathrm{~km}^{2}\right)$ and bushes $\left(877.8 \mathrm{~km}^{2}\right)$.

The main river in this catchment is Sitnica, the longest river that flows completely within Kosovo, $167 \mathrm{~km}$ length and $13.62 \mathrm{~m}^{3} / \mathrm{s}$ average annual flows. Since it has a relatively small longitudinal slope of $0.054 \%$, Sitnica meanders a lot. It is located at the latitude and longitude coordinates of 42.901667 and 20.873889. Sitnica River originates from Sazlija pond, in the southern part of Kosovo and flows generally to the north, till its confluence into the Ibar River, as its right tributary.

The minimal and maximal values, as well as average annual flow for Sitnica River, measured at hydrometric station in Nedakovc, are as follows:

Table 1. Annual values of water flow $\left(\mathrm{m}^{3} / \mathrm{s}\right)$

\begin{tabular}{|l|l|l|l|l|}
\hline STATION & RIVER & $\begin{array}{l}\mathrm{Q}_{\min } \\
\left(\mathrm{m}^{3} / \mathrm{s}\right)\end{array}$ & $\begin{array}{l}\mathrm{Q}_{\text {avg }} \\
\left(\mathrm{m}^{3} / \mathrm{s}\right)\end{array}$ & $\begin{array}{l}\mathrm{Q}_{\max } \\
\left(\mathrm{m}^{3} / \mathrm{s}\right)\end{array}$ \\
\hline NEDAKOVC & SITNICA & 0.50 & 13.62 & 328.0 \\
\hline
\end{tabular}


Sitnica flows through the Kosovo coal basin, west of Prishtina. In this area, Sitnica receives some of its most important tributaries, the Drenica River from the left and Prishtevka and Gracanka rivers from the right. The other tributaries that flow into Sitnica are also rivers Llapi, Shtimlanka, Sazlia and Matica, with their catchment's areas given in the following table.

Table 2. Sitnica River's main tributaries

\begin{tabular}{|l|l|l|}
\hline RIVER & $\begin{array}{l}\text { MAIN TRIBUTARIES } \\
\text { TRIBUTARIES }\end{array}$ & $\begin{array}{l}\text { AREA } \\
\left(\mathrm{km}^{2}\right)\end{array}$ \\
\hline \multirow{4}{*}{ SITNICA } & Llap & 1432.52 \\
\cline { 2 - 3 } & Prishtevka & 109.32 \\
\cline { 2 - 3 } & Drenica & 442.0 \\
\cline { 2 - 3 } & Gracanka & 180.93 \\
\cline { 2 - 3 } & Shtimlanka & 127.6 \\
\cline { 2 - 3 } & Sazlia and Matica & 141.5 \\
\hline
\end{tabular}

While flowing through the catchment Sitnica River is subject to many pollution sources. In urban reaches of this river, the untreated domestic and industrial waste waters are discharged directly into it. On the other hand, agriculture is a non point source contributor to those surface waters as well as direct dumping of solid waste in the vicinity of the river, erosion, mining activities as well as leachate from waste disposal areas.

Sitnica is the river with higher number of deployment sites in the Sitnica Catchment, as it is known to be subject to at least 32 polluters (Regional Environmental Centre, 2000). Except for the discharge of the domestic sewage in those rivers, they are endangered by the various industrial activities such as ironmongery, food and textile industry, slaughterhouse, metallurgical and chemical industry as well as energy industry. The map of deployment sites in Sitnica River is given below.

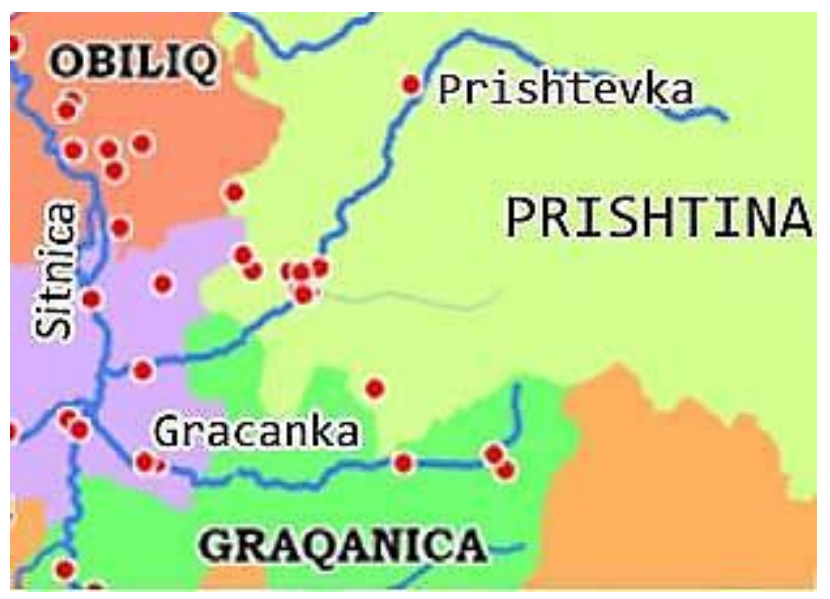

Fig. 2. Map of deployment sites Source: (Regional Environmental Centre, 2000)

Considering all the mentioned facts and hydrological data, Sitnica River is selected for the development of turbidity to TSS relationship for this work. The selected sampling location was the reach of Sitnica River in Vragoli, after the outfalls of Prishtevka and Gracanka rivers.

\section{Methods}

\subsection{Sampling}

Water samples were collected in chosen locations during October, 2010. Due to the financial restrictions and the need for fewer personnel in the field, the most costeffective method for sample collection was chosen. This is the main reason that the grab sampling was performed in this sampling site.

Samples were taken under stable environmental conditions, not following rainstorm or extremely high discharge event. Samples were collected manually in clean polyethylene bottles, volume $1000 \mathrm{ml}$, with the use of sampling rod, since it is proved to be the quickest procedure, needing less rinsing than the bailer and bucket combination. After the sample bottles were placed into the holders, they were inverted and half filled at $20 \mathrm{~cm}$ below the water surface. The lid was placed on sample bottles and they were shaken to ensure thoroughly rinsing of the lids and bottles. The content of the bottles was then discarded away from sampling site and this process was repeated three times.

The water samples collected were labelled with the time, date and site and placed in the cooler. For the determination of turbidity to TSS relationship, the sub sampling was done in a laboratory. Subsamples were prepared in order to have different values of turbidity and TSS, and after the preparation were preserved and refrigerated under a temperature of $4^{\circ} \mathrm{C}$ (American Public Health Association, 2005). Those subsamples were then sent to the Hydro Meteorological Institute of Kosova (HIK) for the analyses of turbidity and TSS concentrations.

\subsection{Statistical Analyses}

It is well known that statistical methods are of a crucial importance in the successes of water quality monitoring. In general, water research studies require large data bases with a range of parameters. Therefore, the surface water quality monitoring can be improved by the use of clear mathematical relationships between key parameters and their surrogate parameters. This is possible due to the fact that these relationships reduce the number of key water quality parameters that are to be monitored.

The objective of this work was to develop linear regression model between turbidity and total suspended solids based on the use of a statistical technique, known as linear regression analyses.

As shown in the following chart, the data from the laboratory analyses were plotted in Excel 2007 from which a linear regression equation was derived, for conversion of all recorded turbidity data to TSS values. In our case, the dependent variable $\mathrm{Y}$ is the total suspended solids, the TSS response variable, while independent variable $\mathrm{X}$ is turbidity. 


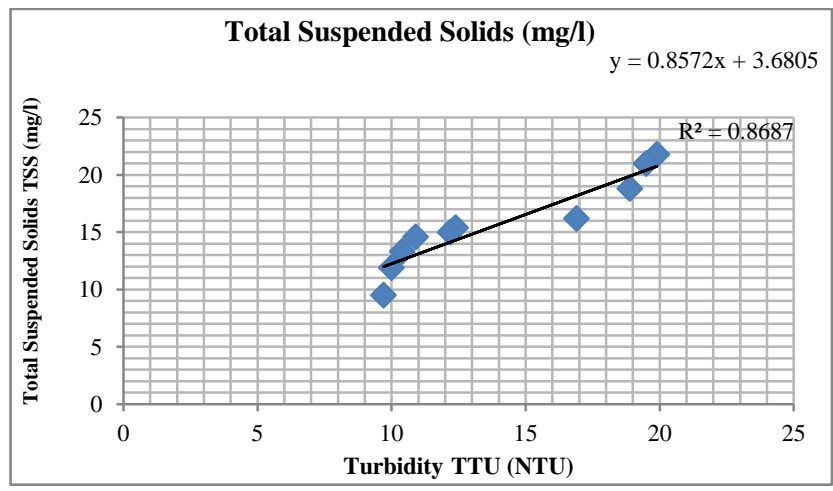

Fig. 3. Correlation between turbidity and Total Suspended Solids

\section{Results and Discussions}

As it can be noticed from the graph, the correlation between turbidity and total suspended solids for a study site is a positive relationship and it is as follows:

$\operatorname{TSS}(\mathrm{mg} / \mathrm{l})=0.8572 \mathrm{TTU}(\mathrm{NTU})+3.6805$

Table 3. Variable Description

\begin{tabular}{|l|l|l|}
\hline Variable & Unit & Description \\
\hline TTU & NTU & Turbidity \\
\hline TSS & $(\mathrm{mg} / \mathrm{l})$ & Total Suspended Solids \\
\hline
\end{tabular}

An explanatory variable, such as turbidity in this relationship, can be used to compute the response variable Total Suspended Sediments.

Since the predictive ability of the relationship can be assessed based on the coefficient of determination $\left(\mathrm{R}^{2}\right)$, than for the selected location there is a strong correlation between turbidity and TSS (correlation coefficient of 0.868).

As it is evident in the same graph, we can conclude that the prediction of TSS based on turbidity readings, for a given site is quite reasonable.

\section{Conclusions}

Since the frequent sampling and laboratory analyses of the TSS are time consuming and require a considerable budget means, than the developed relationship would serve its best. The utility of this model will be in predicting TSS levels from a measured turbidity in a given location, when in fact the slight changes in TSS concentration have large effects on turbidity reading. Also, the same relationship would be suitable for other sites in an event, where the coefficients for the developed models in each site are identical.

As an outcome of this study, this relationship can be used for measuring stream bank erosion, nutrient, contaminant transport and sediment loads.

The benefits of water quality measurements using this relationship include the ability for quick action in response to negative water quality changes. This will result in a reduction of overall monitoring costs. Additionally, when surface water quality criteria are exceeded then the immediate action can be taken.

The outcome of this research, the developed turbidity to TSS relationship can be used in many areas. The relationship can help in documenting the effectiveness of stream restoration projects. In agriculture, it can help in monitoring suspended solids, in order to reduce non point source pollution. The data gained from this relationship can be used to identify water bodies impaired by suspended solids, to prioritize areas for additional monitoring and research, to detect trends of increasing or decreasing erosion in a watershed.

Finally, the positive value of this research is that the linear regression model relating turbidity to TSS may be a useful tool in hands of an engineer in controlling and regulating sediment Total Maximum Daily Loads in an urban stream.

As a result, compliance with water quality standards and regulations that are based on concentration and load estimates can be determined with more certainty.

\section{References}

American Public Health Association APHA, (2005), Standard Methods for the Examination Of water And Wastewter.

Islami H., (2003), Demographic Dimension in Kosovo - State of the Environment Report [Conference]. - Prishtina, Kosovo.

James J. Packman, Karen Comings, Derek Booth, (1999), using Turbidity to Determine Total Suspended Solids in Urbanizing Streams in the Puget Lowlands [Conference]. Washington, USA.

Kosova Hidrometeorological Institute, (2010), Prishtina, Kosovo.

Kusari Laura, (2012), Turbidity Measurements as a Surrogate to TSS in Urban River Reaches [Conference] // Balwois. Ohrid, Macedonia

Ministry of Environment and Spatial Planning Ministry of Environment and Spatial Spatial Development Strategy 2010 2020+ , (2010), Prishtina, Kosovo, Ministry of Environment and Spatial Planning.

Regional Environmental Centre, Kosovo Environmental Protection Agency, (2000), Kosovo Water Polluters Cadastre, Prishtina, Kosovo. 